Canadian

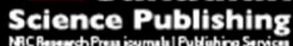

Applied Physiology, Nutrition, and Metabolism Physiologie appliquée, nutrition et métabolisme

\title{
Cardiometabolic Risk Markers of Normal Weight and Excess Body Weight in Brazilian Adolescents
}

\begin{tabular}{|c|c|}
\hline Journal: & Applied Physiology, Nutrition, and Metabolism \\
\hline Manuscript ID & apnm-2015-0632.R1 \\
\hline Manuscript Type: & Article \\
\hline Date Submitted by the Author: & $15-J a n-2016$ \\
\hline Complete List of Authors: & $\begin{array}{l}\text { Mastroeni, Silmara; University of Joinville Region - UNIVILLE, Physical } \\
\text { Education; University of Alberta, Population Health Intervention Research } \\
\text { Unit, School of Public Health, } \\
\text { Mastroeni, Marco; University of Joinville Region, UNIVILLE, Biological } \\
\text { Sciences; University of Alberta, School of Public Health, Population Health } \\
\text { Intervention Research Unit } \\
\text { Goncalves, Muryel; University of Joinville Region, UNIVILLE } \\
\text { Debortoli, Guilherme; University of Joinville Region, UNIVILLE } \\
\text { Silva, Nilza; University of Sao Paulo, USP, Epidemiology } \\
\text { Bernal, Regina; University of Sao Paulo, USP, Epidemiology } \\
\text { Adamovski, Maristela; University of Joinville Region, UNIVILLE } \\
\text { Veugelers, Paul; University of Alberta, School of Public Health, Population } \\
\text { Health Intervention Research Unit } \\
\text { Rondó, Patricia; University of Sao Paulo, USP, Nutrition, School of Public } \\
\text { Health }\end{array}$ \\
\hline Keyword: & $\begin{array}{l}\text { adolescents, cardiovascular disease, overweight, cardiometabolic markers, } \\
\text { leptin }\end{array}$ \\
\hline
\end{tabular}

\section{SCHOLARONE"}

Manuscripts 
Title: Cardiometabolic Risk Markers of Normal Weight and Excess Body Weight in Brazilian Adolescents

Authors: Silmara Salete de Barros Mastroeni, Marco Fabio Mastroeni, Muryel de Carvalho Gonçalves, Guilherme Debortoli, Nilza Nunes da Silva, Regina Tomie Ivata Bernal, Maristela Adamovski, Paul J. Veugelers, and Patrícia Helen de Carvalho Rondó

\section{Corresponding author:}

Silmara S.B.S. Mastroeni. Department of Physical Education, University of Joinville Region, Rua Paulo Malschitzki, nº 10, Joinville, SC, Brazil, 89.219-710. Phone: 5547 3461-9026. Email: silmara.mastroeni@univille.br

\section{Affiliations:}

S.S.B.S. Mastroeni. Department of Physical Education, University of Joinville Region, Rua Paulo Malschitzki, nº 10, Joinville, 89.219-710, Brazil; Population Health Intervention Research Unit, School of Public Health, University of Alberta, 3-50 University Terrace, 8303 - 112 St, Edmonton, T6G 2T4, Canada. E-mail: silmara.mastroeni@univille.br M.F. Mastroeni. Post-graduation Program in Health and Environment, University of Joinville Region, Rua Paulo Malschitzki, nº 10, Joinville, 89.219-710, Brazil; Population Health Intervention Research Unit, School of Public Health, University of Alberta, 3-50 University Terrace, 8303 - 112 St, Edmonton, T6G 2T4, Canada. E-mail: $\underline{\text { marco.mastroeni@univille.br }}$

M.C. Gonçalves. Department of Biological Sciences, University of Joinville Region, Rua Paulo Malschitzki, nº 10, Joinville, 89.219-710, Brazil.E-mail: leyrum@gmail.com 
G. Debortoli. Department of Biological Sciences, University of Joinville Region, Rua Paulo Malschitzki, nº 10, Joinville, 89.219-710, Brazil.E-mail: guilhermedebortoli@yahoo.com.br N.N da Silva. Department of Epidemiology, School of Public Health, University of São Paulo, Av. Dr. Arnaldo, no 715, São Paulo, 01246-904, Brazil. E-mail: ndsilva@usp.br R.T.I. Bernal. Department of Epidemiology, School of Public Health, University of São Paulo, Av. Dr. Arnaldo, no 715, São Paulo, 01246-904, Brazil. E-mail: rbernal@usp.br M. Adamowski. Department of Pharmacy, University of Joinville Region. Rua Paulo Malschitzki, nº 10. Joinville, 89.219-710, Brazil. E-mail: maris_imuno@yahoo.com.br P.J. Veugelers. Population Health Intervention Research Unit, School of Public Health, University of Alberta, 3-50 University Terrace, 8303 - 112 St, Edmonton, T6G 2T4, Canada. E-mail: paul.veugelers@,ualberta.ca

P.H.C. Rondó. Department of Nutrition, School of Public Health, University of São Paulo, Av. Dr. Arnaldo, no 715, São Paulo, 01246-904, Brazil. E-mail: phcrondo@usp.br 


\begin{abstract}
Excess body weight leads to a variety of metabolic changes and increases the risk for cardiovascular diseases (CVD) in adulthood. The objective of this study was to investigate the presence of risk markers for CVD among Brazilian adolescents of normal weight and with excess body weight. The markers included blood pressure, C-reactive protein, homocysteine, tumor necrosis factor alpha, fibrinogen, fasting insulin and glucose, homeostasis model assessment insulin resistance (HOMA-IR), leptin, total cholesterol, low-density lipoprotein cholesterol (LDL-c), high-density lipoprotein cholesterol (HDL-c), and triglycerides. We calculated odds ratios $(\mathrm{OR})$ using logistic regression and adjusted for the potential confounders such as age, sex, physical activity and socioeconomic background. Compared to normal weight subjects, overweight/obese adolescents were more likely to have higher systolic blood pressure $(\mathrm{OR}=3.49, \mathrm{p}<0.001)$, fasting insulin $(\mathrm{OR}=8.03, \mathrm{p}<0.001)$, HOMAIR $(O R=8.03, p<0.001)$, leptin $(O R=5.55, p<0.001)$ and LDL-c $(O R=5.50, p<0.001)$, and to have lower serum HDL-c concentrations $(\mathrm{OR}=2.76, \mathrm{p}=0.004)$. After adjustment for confounders, the estimates did not change substantially, except for leptin for which the risk associated with overweight increased to 11.09 (95\% CI: 4.05-30.35). In conclusion, excess body weight in adolescents exhibits strong associations with several markers that are established as causes of CVD in adults. This observation stresses the importance of primary prevention and of maintaining a healthy body weight throughout adolescence in order to reduce the global burden of CVD.
\end{abstract}

Key words: adolescents, cardiovascular disease, overweight, obese, leptin, cardiometabolic markers, blood pressure, cholesterol, insulin, leptin. 


\section{Introduction}

The prevalence of excess body weight (overweight and obesity) in childhood and adolescence has increased globally. In Brazil, in 2010, 20.6\% of adolescents were classified as having excess body weight, with $5.0 \%$ of them being obese (Brasil 2010). Excess body weight in adolescence determines the risk for excess body weight in adulthood. Excess body weight in adulthood leads to a variety of metabolic changes, to insulin resistance and inflammation, produces changes in cardiometabolic risk markers, and increases the risk for cardiovascular diseases (CVD) (Mathieu et al. 2009; Bastien et al. 2014; McGown et al. 2014).

The pathophysiological processes linking excess body weight to atherosclerosis and CVD involve factors such as visceral obesity, excess ectopic fat, insulin resistance, atherogenic dyslipidemia, and hypertension (Bastien et al. 2014). Elevated circulating inflammatory markers predict an unfavorable course of acute coronary syndromes and represent new targets for therapy (Libby et al. 2002). Furthermore, there is evidence that adipose tissue is a key organ in the production and regulation of endocrine and paracrine hormones modulating both inflammation and metabolic processes (Bastien et al. 2014). Hormones such as leptin, along with inflammatory biomarkers such as high-sensitivity Creactive protein (hs-CRP) and tumor necrosis factor alpha (TNF- $\alpha)$, contribute to the inflammatory profile in the process of obesity (Bastien et al. 2014), and therefore to the risk for cardiometabolic diseases (Lowe 2001).

Studies of the past decade have revealed that these pathophysiological processes are not limited to obese adults, but that, in fact, elevated cardiometabolic risk markers are increasingly common among adolescents (Lobstein et al. 2004). Most of the studies were conducted in high-income countries where the prevalence of obesity has gradually increased over the past five decades (Lobstein et al. 2004). Brazil is a country of upper middle income 
that has experienced a rapid nutritional transformation and a more recent rapidly developing obesity epidemic with current obesity rates of the same magnitude as reported for North America (Monteiro et al. 1995; Monteiro et al. 2002; Lobstein et al. 2004; Ng et al. 2014). Therefore, the objective of the present study was to investigate whether excess body weight among Brazilian adolescents is paralleled by an increased cardiometabolic risk profile.

\section{Material and Methods}

\section{Study population}

The study population consisted of a cross-sectional sample of 15-17-year-old high school students living in the city of Joinville, Santa Catarina, Brazil. The first phase of the study was carried out between May and November 2007. Joinville has 28 schools with 436 classes. A total of 2,195 students agreed to participate in the study, gave written informed consent, and completed a short survey of socioeconomic and demographic characteristics. They also took home an informed consent form to be completed and signed by their parents/guardians, which was returned by $1,104(50.3 \%)$ of them.

The second phase of data collection took place between September and November 2008. All 1,104 participants of the first phase were invited to participate in the second phase of the study. They were contacted by phone and by a personal visit to their residence, and were informed about the day and place of data collection. At the end of the study, 222 students had attended data collection. Assessments during this phase included weight and height, blood pressure, and serum levels of hs-CRP, homocysteine, TNF- $\alpha$, fibrinogen, fasting insulin, fasting glucose, leptin, total cholesterol (TC), low-density lipoprotein cholesterol (LDL-c), high-density lipoprotein cholesterol (HDL-c), and triglycerides (TG). 
The research was carried out in accordance with the Declaration of Helsinki and the Ethics Committee of the University of Joinville Region approved the study (Case No. 005/2007).

\section{Data collection}

The anthropometric measurements were taken early in the morning after an overnight fast. The adolescents were weighed on a Filizola ${ }^{\circledR}$ digital scale (Curitiba, PR, Brazil) with a capacity of $180 \mathrm{~kg}$ to the nearest $0.1 \mathrm{~kg}$, using light clothes (t-shirt and short), without shoes and accessories (caps and jewelry). Height was measured with a 200-cm Cardiomed $^{\circledR}$ stadiometer (Curitiba, PR, Brazil) to the nearest $0.1 \mathrm{~cm}$. The anthropometric measurements were performed according to the recommendations (Gordon et al. 1988)), and performed in duplicate considering the average as the final measure. We calculated body mass index (BMI) [weight $(\mathrm{kg}) /$ height $\left(\mathrm{m}^{2}\right)$ ] and used the World Health Organization's age- and sex-specific cutoffs to create two groups: $>85^{\text {th }}$ percentile for participants considered to be overweight/obese and $\leq 85^{\text {th }}$ percentile for participants considered to be underweight/normal weight (de Onis et al. 2007).

Physical activity was classified according to the International Physical Activity Questionnaire (IPAQ) (Craig et al. 2003). Income was evaluated using a Brazilian instrument that estimates the purchasing power of urban individuals and families (Associação Brasileira de Empresas de Pesquisa 2003). Information about income and physical activity was collected by interview.

Diastolic (DBP) and systolic blood pressure (SBP) was measured using the HDI/Pulse Wave $^{\mathrm{TM}}$ CR-2000 Research Cardiovascular Profiling System (Hypertension Diagnostic ${ }^{\circledR}$, Inc., Eagan, MN, USA). The examination was performed with the participants lying on a gurney after a 10-min resting period. SBP and DBP were categorized according to the criteria 
proposed by the Fourth Report on the Diagnosis, Evaluation, and Treatment of High Blood Pressure in Children and Adolescents (National High Blood Pressure Education Program Working Group on High Blood Pressure in Children and Adolescents 2004).

\section{Biochemical analysis}

Approximately $15 \mathrm{ml}$ of venous blood was drawn from an antecubital vein of each individual in the morning after an overnight fast. Within $30 \mathrm{~min}$, the remaining blood serum was separated by a 10 min centrifugation at $3500 \mathrm{rpm}$ and $4^{\circ} \mathrm{C}$. The sample was immediately aliquoted and frozen at $-70^{\circ} \mathrm{C}$ until the time of analysis.

Fasting glucose, LDL-c and HDL-c analyses were performed by the colorimetric enzymatic method with a Bayer ADVIA 1650 automated analyzer, using GLUO, D-LDL and D-HDL kits, respectively (Siemens Diagnostics, Tarrytown, NY, USA). Total cholesterol and TG were analyzed with the Bayer ADVIA Centaur automated analyzer using Cholesterol and Triglycerides Liquiform kits, respectively (Labtest Diagnostica ${ }^{\circledR}$, Vista Alegre, MG, Brazil). Fasting glycemia was classified based on the criteria currently adopted for the diagnosis of type 2 diabetes, which are the same for adults and children (Genuth et al. 2003). Total cholesterol and fractions and TG were classified according to the recommendations of the First Brazilian Guidelines for the Prevention of Atherosclerosis during Childhood and Adolescence (Giuliano 2006). Vitamin B12, homocysteine and insulin were assayed by chemoluminescence with the Bayer ADVIA Centaur automated analyzer using the HCY (analytical sensitivity of $0.13 \mathrm{mg} / \mathrm{L}$ ), VB12 (analytical sensitivity of $45 \mathrm{pg} / \mathrm{mL}$ ) and IRI (analytical sensitivity of $0.5 \mu \mathrm{IU} / \mathrm{mL}$ ) Bayer ADVIA kits, respectively (Siemens Diagnostics $^{\circledR}$ ). Homeostatic model assessment for insulin resistance (HOMA-IR) was calculated using the equation HOMA-IR $=$ fasting insulin $(\mu \mathrm{IU} / \mathrm{mL}) \times$ fasting glucose $(\mathrm{mmol} / \mathrm{L}) / 22.5$. Insulin resistance was considered to be present when HOMA $\geq 2.5$ (Valerio et 
al. 2006). A wide range C-reactive protein (wr-CRP) test was performed by a latex-enhanced immunoturbidimetric assay with the Bayer ADVIA 1650 automated analyzer using the Bayer ADVIA kit for wr-CRP (Siemens Diagnostics ${ }^{\circledR}$ ) and an analytical sensitivity of $0.12 \mathrm{mg} / \mathrm{L}$. Since no reference values for CRP exist in the international literature for adolescents, we used the values for adults (Pearson et al. 2003). Human leptin levels were determined by ELISA using an EZHL-80SK kit (Millipore Corporation ${ }^{\circledR}$, St. Charles, MO, USA) with $0.5 \mathrm{ng} / \mathrm{mL}$ sensitivity. Fibrinogen was estimated by the Clauss method using a commercial fibrinogen kit (Wiener lab ${ }^{\circledR}$, Rosário, Argentina) with an analytical sensitivity of $10 \mathrm{mg} / \mathrm{L}$. All measurements were performed at a laboratory accredited by the Brazilian Society of Clinical Analysis.

\section{Statistical analysis}

Data were analyzed statistically using the IBM Corp. Released 2013, IBM SPSS Statistics for Macintosh $^{\circledR}$, Version 22.0 (IBM Corp. Armonk, NY, USA.). Continuous variables are reported as mean and standard deviation (SD), or median and interquartile range. Central tendency and absolute and relative frequencies were estimated as descriptive statistics. Differences between underweight/normal weight and overweight/obese groups were performed by Mann-Whitney test. Normality was checked using the Kolmogorov-Smirnov test. Adverse levels of TC, LDL-c, triglycerides, hs-CRP, homocysteine, fibrinogen, blood pressure, leptin, TNF- $\alpha$, fasting insulin, and HOMA-IR were defined as values at or above the $75^{\text {th }}$ percentile. For HDL-c concentrations, the adverse level was defined as values at or below the $25^{\text {th }}$ percentile. The use of the $75^{\text {th }}$ and $25^{\text {th }}$ percentiles to define adverse levels of CVD risk factors permitted us to conduct multivariable logistic regression analyses due to a sufficient number of participants with adverse levels (Maximova et al. 2013). These 
thresholds were similar to those used in other studies with adolescents (Lambert et al. 2004; Maximova et al. 2013).

The relationships between BMI and the above cardiometabolic risk factors were assessed using the Spearman correlation coefficient. To further investigate the association of body weight status (underweight/normal weight versus overweight/obese) with each of the cardiometabolic risk factors, we calculated odds ratios (OR) and $95 \%$ confidence intervals (95\%CI) using logistic regression. In these regression analyses, we adjusted for the following confounders: age, sex, family income, mother's education, and physical activity. The analysis of homocysteine was further adjusted for vitamin B12 due to the confounding influence of Vitamin B12 on the homocysteine metabolism (Jacques et al. 2001). All analyses were considered to be significant when $\mathrm{p}<0.05$.

\section{Results}

The characteristics of the study population are listed in Table 1. The most frequent characteristics of our study population were 16 years of age, female sex, normal weight, a moderate level of physical activity, mother's education of $<9$ years, and a family income of 3 to 8 times the minimum Brazilian wage (MBW). One MBW equals approximately US\$ 181.00 per month. Table 1 further shows that $20.3 \%$ of the participants had excess body weight.

Regarding the cardiometabolic characteristics listed in Table 2, $12.6 \%$ of the adolescents had high SBP, 6.6\% had levels of hs-CRP within the moderate or high cardiovascular risk range, and 5.1\%, 38.9\% and $8.7 \%$ had elevated concentrations of homocysteine, TNF- $\alpha$ and fibrinogen, respectively. Most students had elevated glucose levels $(62.9 \% ; \geq 100 \mathrm{mg} / \mathrm{dL})$, and $46.3 \%$ of the adolescents had insulin resistance (HOMA-IR $\geq 2.5$ ). Elevated levels of leptin $(29.1 \% ; \geq 20 \mathrm{ng} / \mathrm{dL}), \mathrm{TC}(58.3 \% ; \geq 170 \mathrm{mg} / \mathrm{dL})$, LDL-c $(17.9 \% ; \geq 130$ 
$\mathrm{mg} / \mathrm{dL})$ and TG (14.7\%; $\geq 130 \mathrm{mg} / \mathrm{dL})$ were also observed. Twelve (5.5\%) adolescents had HDL-c below the recommended value, i.e., $<45 \mathrm{mg} / \mathrm{dL}$ (Table 2). Overweight/obese participants showed significantly $(p<0.05)$ higher median values of SBP, DBP, insulin, glucose, HOMA, leptin, LDL-c and triglycerides compared to underweight/normal weight adolescents, except for HDL-c. We also observed higher frequencies of elevated values in overweight/obese participants, except for homocysteine (Table 2).

The Spearman correlation coefficients for BMI and cardiometabolic risk markers are shown in Table 3. BMI was positively and significantly $(\mathrm{p}<0.01)$ correlated with SBP, fibrinogen, fasting insulin, HOMA-IR, leptin, LDL-c and TG, and negatively correlated with HDL-c (Table 3).

Table 4 summarizes the results of multivariable logistic regression analysis that considered cardiometabolic risk factors $\geq 75^{\text {th }}$ percentile as outcomes. In the unadjusted analysis, adolescents with excess body weight were significantly more likely to have higher values $\left(\geq 75^{\text {th }}\right.$ percentile $)$ of SBP $(\mathrm{OR}=3.49)$, fasting insulin $(\mathrm{OR}=8.03)$, HOMA-IR $(\mathrm{OR}=$ 8.03), leptin $(\mathrm{OR}=5.55)$, and LDL-c $(\mathrm{OR}=5.50)$ compared to those with normal weight. Lower HDL-c levels $\left(<25^{\text {th }}\right.$ percentile) were associated with excess body weight when compared to normal weight adolescents $(\mathrm{OR}=2.76 ; 95 \% \mathrm{CI}$ : 1.37-5.56). Adjustment for age, female sex, family income, mother's education or physical activity did not substantially alter the estimates, except for the risk of high leptin concentrations, which increased from 5.50 to $11.09(\mathrm{p}<0.01)($ Table 4).

\section{Discussion}

In this study, we show that Brazilian adolescents with excess body weight have several cardiometabolic risk factors. The prevalence of these risk factors may in fact be more common than previously reported (Weiss et al. 2004). Our study confirms reports of 
adolescents residing in high-income countries (Freedman et al. 1999; Herder et al. 2007;

Caserta et al. 2010; Maximova et al. 2013), in Brazil (Brasil et al. 2007; Silva et al. 2010;

Cardoso et al. 2014; Azevedo et al. 2015), and in other upper middle-income countries

(Kelishadi et al. 2007; Agirbasli et al. 2015), which have shown increases in risk markers at an early age. In addition, unlike previous studies, the present study estimated the likelihood of Brazilian adolescents with excess body weight having altered values of cardiometabolic risk markers considering 14 different markers.

Our results also show that in the presence of excess body weight and after adjusting for age, female sex, family income, mother's education and physical activity, there was an increase in the risk of insulin resistance - HOMA-IR index $(O R=8.84 ; \mathrm{p}<0.001)$. This information offers an opportunity to emphasize the importance of treating excess body weight at an early age in order to prevent future consequences. Insulin resistance is the most common metabolic alteration related to obesity and represents an important link between obesity and other cardiometabolic complications, including metabolic syndrome and type 2 diabetes mellitus (Herder et al. 2007).

Independent of body weight, the prevalence of insulin resistance observed here (46.3\%) was alarming. The high prevalence of insulin resistance observed in the present study agrees with findings obtained for Brazilian and Chinese adolescents and may predict an increasing burden of metabolic disease in the near future (Rizzo et al. 2013; Yin et al. 2013). HOMA-IR may be useful for the early evaluation of insulin resistance in adolescents and could have a long-term benefit for preventive and diagnostic therapeutic interventions (Yin et al. 2013). On the other hand, there are numerous criticisms regarding the use of HOMA-IR, the most important being the lack of standardization of insulin measurements, which impairs comparisons with other studies or populations (Yin et al. 2013). Furthermore, the different cutoff points used in the literature make it difficult to compare studies. 
Another point to be noted in this study is the effect of excess body weight on leptin levels. Leptin is a hormone primarily synthesized and produced by adipocytes and has been identified as a key factor in maintaining energy balance and overall body weight composition (Venner et al. 2006). Elevated circulating leptin levels are independently associated with the incidence of CVD (Koh et al. 2008), including insulin signaling, immunity, vascular function, and blood pressure regulation (Martin et al. 2008). In some contexts leptin seems to promote both atherogenesis and insulin resistance or, in contrast, may have antiatherogenic and insulin-sensitizing effects (Koh et al. 2008). These opposite actions of leptin are maintained in balance under healthy conditions but not in pathological conditions such as obesity, in which the change in leptin actions may stimulate vascular inflammation, oxidative stress, and vascular smooth muscle hypertrophy (Koh et al. 2008). These actions may contribute to the pathogenesis of hypertension, atherosclerosis, left ventricular hypertrophy, and type 2 diabetes mellitus (Koh et al. 2008).

Considering that atherosclerosis is increasingly viewed as an inflammatory disease caused by lipoproteins, metabolic signals, hemodynamic stress, and the integrated activity of immune cells and inflammatory cytokines, it is interesting to note that leptin and inflammatory pathways demonstrate reciprocal modulation and shared association with cardiovascular risk (Martin et al. 2008). Leptin is also a common mediator of the neuroendocrine and immune systems. In the immune system, leptin, in combination with CRP and interleukins 1 (IL-1) and 6 (IL-6), can act as an early acute-phase reactant produced at high levels during inflammation, which can be induced by other inflammatory mediators such as TNF- $\alpha$ and IL-1 (La Cava and Matarese 2004). Therefore, although leptin has welldocumented proinflammatory properties, it might act as an acute-phase reactant in some conditions and not in others (La Cava and Matarese 2004). In the present study, the adolescents with excess body weight showed an 11 times higher likelihood of increased leptin 
levels compared with normal participants. This finding is in agreement with the theory of a leptin-resistant state existing in most overweight/obese humans when there is a defect within the leptin signaling cascade (Venner et al. 2006).

While there is no global consensus about the definition of obesity from a biological standpoint, values used in research settings have proven useful at identifying people with risk factors for developing numerous other chronic diseases, such as type 2 diabetes, heart disease, and non-alcoholic fatty liver disease (Jean et al. 2014; McGown et al. 2014). Excess body weight must be studied as a primary condition rather than as an accidental condition derived from other diseases.

Over the last decade, important contributions have been made to the understanding of the different functions of adipose tissue. However, the interplay between the signaling cascades involved in the major outcomes of overweight/obese individuals, such as inflammation, insulin resistance and hormonal deregulation, has yet to be elucidated (McGown et al. 2014).

This study has several strengths that should be mentioned, including the collection of prospective data and the ability to adjust for several important confounding factors. All data, including anthropometric measures, were collected by the same research group, which helps reduce possible bias. In addition, we observed that $69.7 \%$ of the adolescents had TG concentration $<100 \mathrm{mg} / \mathrm{dL}$, i.e., normal values for fasting, confirming compliance with the request to fast. However, the values observed for glucose concentrations were high in both weight categories analyzed. One may speculate that some participants had fasted, but did consume some sugary drinks despite our instructions that only water consumption was allowed. This may have affected our estimates of glucose, insulin, and HOMA-IR. Other limitations may pertain to BMI as a means to classify adolescents as being of normal weight or having excess body weight. BMI allows only an indirect evaluation of adiposity and cannot 
distinguish fat mass from fat-free mass. Furthermore, we acknowledge the relative low response rate and the imbalance between sexes may limit the generalizability of our findings. Lastly, the cross-sectional design does not allow conclusions related to causality.

In conclusion, excess body weight in this group of Brazilian adolescents exhibits strong associations with markers that are established as causes of CVD in adults. This underlines the importance of primary prevention early in life and effective management of adolescents with cardiometabolic risk markers. It also supports the notion of a cumulative risk for CVD throughout childhood, adolescence and adulthood, which applies globally and calls for global strategies for primary prevention.

\section{Acknowledgments}

We thank the Gimenes Laboratory of Joinville for processing the biochemical data and the Secretary of Education for the city of Joinville, Santa Catarina, for allowing access to the students. The University of Joinville Region (UNIVILLE) and the Research and Innovation Support Foundation of the State of Santa Catarina (FAPESC) supported this work. S.S.B.S. Mastroeni would like to thank P.J. Veugelers for hosting, supporting and supervising her during her postdoctoral fellowship in the Population Health Intervention Research Unit (PHIRU), School of Public Health at the University of Alberta. We also thank the National Council for Scientific and Technological Development (CNPq), Brazil, for granting a scholarship to M.F. Mastroeni. Finally, we would like to thank John P. Ekwaru in the PHIRU for his statistical expertise, and Kerstin Markendorf for the English revision.

\section{Conflicts of interest statement}

The authors declare no conflicts of interest. 


\section{References}

Associação Brasileira de Empresas de Pesquisa (ABEP). 2003. Critério de classificação econômica Brasil. Available from http://www.abep.org [accessed 2 November 2015].

Brasil. 2010. Pesquisa de orçamentos familiares 2008-2009: antropometria e estado nutricional de crianças, adolescentes e adultos no Brasil. Rio de Janeiro: IBGE.

National High Blood Pressure Education Program Working Group on High Blood Pressure in Children and Adolescents. 2004. The fourth report on the diagnosis, evaluation, and treatment of high blood pressure in children and adolescents. Pediatrics 114(2 Suppl 4th Report): 555-76.

Agirbasli, M., Tanrikulu, A., Acar Sevim, B., Azizy, M., and Bekiroglu, N. 2015. Total cholesterol-to-highdensity lipoprotein cholesterol ratio predicts high-sensitivity C-reactive protein levels in Turkish children. J. Clin. Lipidol. 9(2): 195-200. doi:10.1016/j.jacl.2014.12.010.

Azevedo, W.F., Cantalice, A.S., Gonzaga, N.C., Simoes, M.O., Guimaraes, A.L., de Carvalho, D.F., et al. 2015. Fibrinogen: cardiometabolic risk marker in obese or overweight children and adolescents. J. Pediatr. (Rio J) 91(5): 464-70. doi:10.1016/j.jped.2014.11.007.

Bastien, M., Poirier, P., Lemieux, I., and Despres, J.P. 2014. Overview of epidemiology and contribution of obesity to cardiovascular disease. Prog. Cardiovasc. Dis. 56(4): 369-81. doi:10.1016/j.pcad.2013.10.016.

Brasil, A.R., Norton, R.C., Rossetti, M.B., Leão, E., and Mendes, R.P. 2007. C-reactive protein as an indicator of low intensity inflammation in children and adolescents with and without obesity. J. Pediatr. (Rio J) 83(5): 477-480. doi:10.1590/S0021-75572007000600014.

Cardoso, A.d.S., Cardoso, R.O., Carvalho, D.F.d., Collet, N., and Medeiros, C.C.M. 2014. C-reactive protein and cardiometabolic risk factors in overweight or obese children and adolescents. Rev. Nutr. 27(3): 279288. doi:10.1590/1415-52732014000300002.

Caserta, C.A., Pendino, G.M., Alicante, S., Amante, A., Amato, F., Fiorillo, M., et al. 2010. Body mass index, cardiovascular risk factors, and carotid intima-media thickness in a pediatric population in southern Italy. J Pediatr. Gastroenterol. Nutr. 51(2): 216-20. doi:10.1097/MPG.0b013e3181d4c21d.

Craig, C.L., Marshall, A.L., Sjostrom, M., Bauman, A.E., Booth, M.L., Ainsworth, B.E., et al. 2003. International physical activity questionnaire: 12-country reliability and validity. Med. Sci. Sports. Exerc. 35(8): 1381-95. doi:10.1249/01.mss.0000078924.61453.fb.

de Onis, M., Onyango, A.W., Borghi, E., Siyam, A., Nishida, C., and Siekmann, J. 2007. Development of a WHO growth reference for school-aged children and adolescents. Bull. World Health Organ. 85(9): 660-7.

Freedman, D.S., Dietz, W.H., Srinivasan, S.R., and Berenson, G.S. 1999. The relation of overweight to cardiovascular risk factors among children and adolescents: the Bogalusa Heart Study. Pediatrics 103(6 Pt 1): $1175-82$.

Genuth, S., Alberti, K.G., Bennett, P., Buse, J., Defronzo, R., Kahn, R., et al. 2003. Follow-up report on the diagnosis of diabetes mellitus. Diabetes Care 26(11): 3160-7. doi:10.2337/diacare.26.11.3160.

Giuliano, I.C.B., Caramelli, B., Pellanda, L., Duncan, B., Mattos, S. and Fonseca, F. H. 2006. I Guideline for preventing atherosclerosis in childhood and adolescence. Int J Atheroscler 1(1): 1-30.

Gordon, C.C., Chumlea, W.C., and Roche, A.F. 1988. Stature, recumbent length, and weight. In: Lohman TG, Roche AF, Martorell R. Anthropometric Standartization Reference Manual. Champaign, Illinois: Human Kinetics Books.

Herder, C., Schneitler, S., Rathmann, W., Haastert, B., Schneitler, H., Winkler, H., et al. 2007. Low-grade inflammation, obesity, and insulin resistance in adolescents. J. Clin. Endocrinol. Metab. 92(12): 4569-74. doi:10.1210/jc.2007-0955.

Jacques, P.F., Bostom, A.G., Wilson, P.W., Rich, S., Rosenberg, I.H., and Selhub, J. 2001. Determinants of plasma total homocysteine concentration in the Framingham Offspring cohort. Am. J. Clin. Nutr. 73(3): 613-21.

Jean, N., Somers, V.K., Sochor, O., Medina-Inojosa, J., Llano, E.M., and Lopez-Jimenez, F. 2014. Normalweight obesity: implications for cardiovascular health. Curr. Atheroscler. Rep. 16(12): 464. doi:10.1007/s11883-014-0464-7.

Kelishadi, R., Sharifi, M., Khosravi, A., and Adeli, K. 2007. Relationship between C-reactive protein and atherosclerotic risk factors and oxidative stress markers among young persons 10-18 years old. Clin. Chem. 53(3): 456-64. doi:10.1373/clinchem.2006.073668.

Koh, K.K., Park, S.M., and Quon, M.J. 2008. Leptin and cardiovascular disease: response to therapeutic interventions. Circulation 117(25): 3238-49. doi:10.1161/circulationaha.107.741645.

La Cava, A. and Matarese, G. 2004. The weight of leptin in immunity. Nat. Rev. Immunol. 4(5): 371-9. doi:10.1038/nri1350. 
Lambert, M., Delvin, E.E., Paradis, G., O'Loughlin, J., Hanley, J.A., and Levy, E. 2004. C-reactive protein and features of the metabolic syndrome in a population-based sample of children and adolescents. Clin. Chem. 50(10): 1762-8. doi:10.1373/clinchem.2004.036418.

Libby, P., Ridker, P.M., and Maseri, A. 2002. Inflammation and atherosclerosis. Circulation 105(9): 1135-43. doi:10.1161/hc0902.104353

Lobstein, T., Baur, L., and Uauy, R. 2004. Obesity in children and young people: a crisis in public health. Obes. Rev. 5 Suppl 1(4-104). doi:10.1111/j.1467-789X.2004.00133.x.

Lowe, G.D. 2001. The relationship between infection, inflammation, and cardiovascular disease: an overview. Ann. Periodontol. 6(1): 1-8. doi:10.1902/annals.2001.6.1.1.

Martin, S.S., Qasim, A., and Reilly, M.P. 2008. Leptin resistance: a possible interface of inflammation and metabolism in obesity-related cardiovascular disease. J. Am. Coll. Cardiol. 52(15): 1201-10. doi:10.1016/j.jacc.2008.05.060.

Mathieu, P., Poirier, P., Pibarot, P., Lemieux, I., and Despres, J.P. 2009. Visceral obesity: the link among inflammation, hypertension, and cardiovascular disease. Hypertension 53(4): 577-84. doi:10.1161/hypertensionaha.108.110320.

Maximova, K., Kuhle, S., Davidson, Z., Fung, C., and Veugelers, P.J. 2013. Cardiovascular risk-factor profiles of normal and overweight children and adolescents: insights from the Canadian Health Measures Survey. Can. J. Cardiol. 29(8): 976-82. doi:10.1016/j.cjca.2012.08.013.

McGown, C., Birerdinc, A., and Younossi, Z.M. 2014. Adipose tissue as an endocrine organ. Clin Liver Dis 18(1): 41-58. doi:10.1016/j.cld.2013.09.012.

Monteiro, C.A., Conde, W.L., and Popkin, B.M. 2002. Is obesity replacing or adding to undernutrition? Evidence from different social classes in Brazil. Public. Health. Nutr. 5(1A): 105-12. doi:10.1079/phn2001281.

Monteiro, C.A., Mondini, L., de Souza, A.L., and Popkin, B.M. 1995. The nutrition transition in Brazil. Eur. J. Clin. Nutr. 49(2): 105-13.

Ng, M., Fleming, T., Robinson, M., Thomson, B., Graetz, N., Margono, C., et al. 2014. Global, regional, and national prevalence of overweight and obesity in children and adults during 1980-2013: a systematic analysis for the Global Burden of Disease Study 2013. Lancet 384(9945): 766-81. doi:10.1016/s01406736(14)60460-8.

Pearson, T.A., Mensah, G.A., Alexander, R.W., Anderson, J.L., Cannon, R.O., 3rd, Criqui, M., et al. 2003. Markers of inflammation and cardiovascular disease: application to clinical and public health practice: A statement for healthcare professionals from the Centers for Disease Control and Prevention and the American Heart Association. Circulation 107(3): 499-511. doi:10.1161/01.CIR.0000052939.59093.45.

Rizzo, A.C., Goldberg, T.B., Silva, C.C., Kurokawa, C.S., Nunes, H.R., and Corrente, J.E. 2013. Metabolic syndrome risk factors in overweight, obese, and extremely obese Brazilian adolescents. Nutr. J. 12(1): 19. doi:10.1186/1475-2891-12-19.

Silva, I.T., Sanches, L.B., Mello, A.P., and Damasceno, N.R. 2010. Impact of C-reactive protein on cardiovascular risk in adolescents. Arq. Bras. Cardiol. 94(5): 585-91. doi:10.1590/S0066$782 \mathrm{X} 2010005000027$.

Valerio, G., Licenziati, M.R., Iannuzzi, A., Franzese, A., Siani, P., Riccardi, G., et al. 2006. Insulin resistance and impaired glucose tolerance in obese children and adolescents from Southern Italy. Nutr. Metab. Cardiovasc. Dis. 16(4): 279-84. doi:10.1016/j.numecd.2005.12.007.

Venner, A.A., Lyon, M.E., and Doyle-Baker, P.K. 2006. Leptin: a potential biomarker for childhood obesity? Clin Biochem 39(11): 1047-56. doi:10.1016/j.clinbiochem.2006.07.010.

Weiss, R., Dziura, J., Burgert, T.S., Tamborlane, W.V., Taksali, S.E., Yeckel, C.W., et al. 2004. Obesity and the metabolic syndrome in children and adolescents. N. Engl. J. Med. 350(23): 2362-74. doi:10.1056/NEJMoa031049.

Yin, J., Li, M., Xu, L., Wang, Y., Cheng, H., Zhao, X., et al. 2013. Insulin resistance determined by Homeostasis Model Assessment (HOMA) and associations with metabolic syndrome among Chinese children and teenagers. Diabetol. Metab. Syndr. 5(1): 71. doi:10.1186/1758-5996-5-71. 
Table 1. Characteristics of the adolescents studied.

\begin{tabular}{lll}
\hline Characteristics & $\mathrm{n}(\%)$ & Mean $(\mathrm{SD})$ \\
\hline Age (years) & $66(29.7)$ & \\
15 & $130(58.6)$ & \\
16 & $26(11.7)$ & \\
17 & & \\
Sex & $87(39.2)$ & $22.0(4.1)$ \\
Male & $135(60.8)$ & \\
Female & & \\
Body mass index $\left(\mathrm{kg} / \mathrm{m}^{2}\right)$ & $17(7.7)$ & \\
Underweight & $160(72.1)$ & \\
Normal weight & $22(9.9)$ & \\
Overweight & $23(10.4)$ & \\
Obese & $34(15.3)$ & \\
Physical activity & $109(49.1)$ & \\
Low & $79(35.9)$ & \\
Moderate & & \\
High & $127(58.3)$ & \\
Mother's education (years) & $73(33.5)$ & \\
$<9$ & $18(8.3)$ & \\
$9-12$ & $62(27.9)$ & \\
$\geq 12$ & $141(63.5)$ & \\
Family income (MBW) & $19(8.6)$ & \\
$<3$ & & \\
$3-8$ & &
\end{tabular}

Note: SD, standard deviation; MBW, minimum Brazilian wage, which in 2007 was US\$

181.00 per month. 
Table 2. Cardiometabolic profile of the adolescents studied.

\begin{tabular}{|c|c|c|c|}
\hline Characteristics & $\begin{array}{c}\text { Underweight/ } \\
\text { Normal weight } \\
(\mathrm{n}=177)\end{array}$ & $\begin{array}{l}\text { Overweight/Obese } \\
\qquad(\mathrm{n}=45)\end{array}$ & $\begin{array}{c}\text { All } \\
(n=222)\end{array}$ \\
\hline SBP (mmHg), median (IR) & $116(11.0)$ & $122(13.0)^{*}$ & $116(13.0)$ \\
\hline$<95^{\text {th }}$ percentile, $\mathrm{n}(\%)$ & $160(90.4)$ & $34(75.6)$ & $194(87.4)$ \\
\hline$\geq 95^{\text {th }}$ percentile, $\mathrm{n}(\%)$ & $17(9.6)$ & $11(24.4)$ & $28(12.6)$ \\
\hline DBP (mmHg), median (IR) & $61(8.0)$ & $63(7.0)^{*}$ & $62(8.0)$ \\
\hline$<95^{\text {th }}$ percentile, $\mathrm{n}(\%)$ & $176(99.4)$ & $44(97.8)$ & $220(99.1)$ \\
\hline$\geq 95^{\text {th }}$ percentile, $\mathrm{n}(\%)$ & $1(0.6)$ & $1(2.2)$ & $2(0.9)$ \\
\hline CRP (mg/L), median (IR) & $0.1(0.2)$ & $0.2(0.5)$ & $0.1(0.2)$ \\
\hline$<1, \mathrm{n}(\%)$ & $160(93.6)$ & $38(92.7)$ & $198(93.4)$ \\
\hline $1-3, \mathrm{n}(\%)$ & $9(5.3)$ & $2(4.9)$ & $11(5.2)$ \\
\hline$\geq 3, \mathrm{n}(\%)$ & $2(1.1)$ & $1(2.4)$ & $3(1.4)$ \\
\hline Homocysteine $(\mu \mathrm{mol} / \mathrm{L})$, median (IR) & $7.4(4.3)$ & $7.6(3.3)$ & $7.5(4.2)$ \\
\hline$<5, \mathrm{n}(\%)$ & $19(10.9)$ & $5(11.6)$ & $24(11.0)$ \\
\hline $5-15, \mathrm{n}(\%)$ & $146(83.9)$ & $36(83.7)$ & $182(83.9)$ \\
\hline$\geq 15, \mathrm{n}(\%)$ & $9(5.2)$ & $2(4.7)$ & $11(5.1)$ \\
\hline TNF- $\alpha(\mathrm{pg} / \mathrm{mL})$, median (IR) & $3.1(7.0)$ & $3.7(6.1)$ & $3.2(6.4)$ \\
\hline$<1, \mathrm{n}(\%)$ & $16(14.0)$ & $4(13.3)$ & $20(13.9)$ \\
\hline $1-5, \mathrm{n}(\%)$ & $54(47.4)$ & $14(46.7)$ & $68(47.2)$ \\
\hline$\geq 5, \mathrm{n}(\%)$ & $44(38.6)$ & $12(40.0)$ & $56(38.9)$ \\
\hline Fibrinogen $(\mathrm{mg} / \mathrm{dL})$, median (IR) & $255(110.0)$ & $280(95.0)$ & $255(110.0)$ \\
\hline$<200, \mathrm{n}(\%)$ & $43(24.6)$ & $8(18.6)$ & $51(23.4)$ \\
\hline $200-400, \mathrm{n}(\%)$ & $117(66.9)$ & $31(72.1)$ & $148(67.9)$ \\
\hline$\geq 400, \mathrm{n}(\%)$ & $15(8.6)$ & $4(9.3)$ & $19(8.7)$ \\
\hline Insulin $(\mu \mathrm{IU} / \mathrm{mL})$, median (IR) & $8.4(5.7)$ & $15.0(8.6)^{*}$ & $9.5(7.4)$ \\
\hline$<15, \mathrm{n}(\%)$ & $155(89.1)$ & $21(48.7)$ & $177(81.2)$ \\
\hline $15-20, \mathrm{n}(\%)$ & $15(8.6)$ & $14(32.5)$ & $29(13.3)$ \\
\hline$\geq 20, \mathrm{n}(\%)$ & $4(2.3)$ & $8(18.9)$ & $12(5.5)$ \\
\hline Glucose (mg/dL), median (IR) & $102(14.0)$ & $105.0(15.0)^{* *}$ & $103(13.0)$ \\
\hline$<100, \mathrm{n}(\%)$ & $69(39.4)$ & $12(27.9)$ & $81(37.1)$ \\
\hline $100-126$, n $(\%)$ & $105(60.0)$ & $29(67.4)$ & $134(61.5)$ \\
\hline$\geq 126, \mathrm{n}(\%)$ & $1(0.6)$ & $2(4.7)$ & $3(1.4)$ \\
\hline HOMA-IR, median (IR) & $2.1(1.5)$ & $3.9(2.6)^{*}$ & $2.4(1.9)$ \\
\hline$<2.5, \mathrm{n}(\%)$ & $106(60.6)$ & $11(25.6)$ & $117(53.7)$ \\
\hline$\geq 2.5, \mathrm{n}(\%)$ & $69(39.4)$ & $32(74.4)$ & $101(46.3)$ \\
\hline Leptin (ng/dL), median (IR) & $9.9(14.2)$ & $26.2(36.2)^{*}$ & $11.3(19.7)$ \\
\hline$<15, \mathrm{n}(\%)$ & $110(67.5)$ & $13(30.2)$ & $123(59.7)$ \\
\hline $15-20, \mathrm{n}(\%)$ & $20(12.3)$ & $3(7.0)$ & $23(11.2)$ \\
\hline$\geq 20, \mathrm{n}(\%)$ & $33(20.2)$ & $27(62.8)$ & $60(29.1)$ \\
\hline $\mathrm{TC}(\mathrm{mg} / \mathrm{dL})$, median (IR) & $175(42.0)$ & $181(57.0)$ & $176(44.3)$ \\
\hline$<150, \mathrm{n}(\%)$ & $39(22.3)$ & $9(20.9)$ & $48(22.0)$ \\
\hline $150-169$, n $(\%)$ & $36(20.6)$ & $7(16.3)$ & $43(19.7)$ \\
\hline$\geq 170, \mathrm{n}(\%)$ & $100(57.1)$ & $27(62.8)$ & $127(58.3)$ \\
\hline LDL-c (mg/dL), median (IR) & $110(22.0)$ & $127(34.0)^{* *}$ & $112(26.0)$ \\
\hline$<100, \mathrm{n}(\%)$ & $45(25.7)$ & $10(23.3)$ & $55(25.2)$ \\
\hline $100-129$, n $(\%)$ & $108(61.7)$ & $16(37.0)$ & $124(56.9)$ \\
\hline
\end{tabular}




\begin{tabular}{lccc}
$\geq 130, \mathrm{n}(\%)$ & $22(12.6)$ & $17(39.7)$ & $39(17.9)$ \\
HDL-c $(\mathrm{mg} / \mathrm{dL})$, median $(\mathrm{IR})$ & $62(15.0)$ & $56(19.0)^{* *}$ & $62(16.0)$ \\
$\geq 45, \mathrm{n}(\%)$ & $168(96.0)$ & $38(88.4)$ & $206(94.5)$ \\
$<45, \mathrm{n}(\%)$ & $7(4.0)$ & $5(11.6)$ & $12(5.5)$ \\
& & & $85(43.3)$ \\
TG $(\mathrm{mg} / \mathrm{dL})$, median (IR) & $81(41.0)$ & $94(42.0)^{*}$ & $152(69.7)$ \\
$<100, \mathrm{n}(\%)$ & $129(73.8)$ & $23(53.5)$ & $34(15.6)$ \\
$100-129, \mathrm{n}(\%)$ & $23(13.1)$ & $11(25.6)$ & $32(14.7)$ \\
$\geq 130, \mathrm{n}(\%)$ & $23(13.1)$ & $9(20.9)$ & \\
\hline
\end{tabular}

Note: IR, interquartile range; SBP, systolic blood pressure; DBP, diastolic blood pressure; CRP, Creactive protein; TNF- $\alpha$, tumor necrosis factor alpha; HOMA-IR, homeostasis model assessment index-insulin resistance; TC, total cholesterol; LDL-c, low-density lipoprotein cholesterol; HDL-c, high-density lipoprotein cholesterol; TG, triglycerides. * $, \mathrm{p}<0.01{ }^{* *}, \mathrm{p}<0.05$, compared to Underweight/Normal weight group, MannWhitney test. 
Table 3. Spearman's correlation (rho) coefficient between body mass index and cardiometabolic risk markers.

\begin{tabular}{lll}
\hline Variable & Rho & p value \\
\hline Systolic blood pressure $(\mathrm{mm} \mathrm{Hg})$ & 0.257 & $<0.001$ \\
Diastolic blood pressure $(\mathrm{mm} \mathrm{Hg})$ & 0.019 & 0.776 \\
CRP $(\mathrm{mg} / \mathrm{L})$ & 0.102 & 0.139 \\
Homocysteine $(\mu \mathrm{mol} / \mathrm{L})$ & 0.089 & 0.190 \\
TNF- $\alpha(\mathrm{pg} / \mathrm{mL})$ & 0.058 & 0.491 \\
Fibrinogen $(\mathrm{mg} / \mathrm{dL})$ & 0.173 & 0.010 \\
Fasting insulin $(\mu \mathrm{IU} / \mathrm{mL})$ & 0.407 & $<0.001$ \\
Fasting glucose $(\mathrm{mg} / \mathrm{dL})$ & 0.066 & 0.331 \\
HOMA-IR & 0.386 & $<0.001$ \\
Leptin $(\mathrm{ng} / \mathrm{dL})$ & 0.410 & $<0.001$ \\
Total cholesterol $(\mathrm{mg} / \mathrm{dL})$ & 0.070 & 0.301 \\
LDL-c $(\mathrm{mg} / \mathrm{dL})$ & 0.178 & 0.009 \\
HDL-c $(\mathrm{mg} / \mathrm{dL})$ & -0.199 & 0.003 \\
Triglycerides $(\mathrm{mg} / \mathrm{dL})$ & 0.201 & 0.003 \\
\hline
\end{tabular}

Note: CRP, C-reactive protein; TNF- $\alpha$, tumor necrosis factor alpha; HOMA-IR, homeostasis model assessment index-insulin resistance; LDL-c, low-density lipoprotein cholesterol; HDL-c, high-density lipoprotein cholesterol. 
Table 4. Multivariable logistic regression considering cardiometabolic risk factors $\geq 75^{\text {th }}$ percentile as outcome.

\begin{tabular}{|c|c|c|c|c|}
\hline \multirow{2}{*}{ Cardiometabolic risk factor } & \multicolumn{2}{|l|}{ Unadjusted analysis } & \multicolumn{2}{|l|}{ Adjusted analysis $^{*}$} \\
\hline & OR $(95 \% \mathrm{CI})$ & $\mathrm{p}$ value & OR $(95 \% \mathrm{CI})$ & $\mathrm{p}$ value \\
\hline \multicolumn{5}{|l|}{ Systolic blood pressure } \\
\hline Underweight/normal weight & 1.00 (reference) & & 1.00 (reference) & \\
\hline Overweight/obese & $3.49(1.74-7.02)$ & $<0.001$ & $3.24(1.42-7.39)$ & 0.005 \\
\hline \multicolumn{5}{|l|}{ Diastolic blood pressure } \\
\hline Underweight/normal weight & 1.00 (reference) & & 1.00 (reference) & \\
\hline Overweight/obese & $1.38(0.65-2.92)$ & 0.407 & $0.98(0.42-2.26)$ & 0.955 \\
\hline \multicolumn{5}{|l|}{ CRP } \\
\hline Underweight/normal weight & 1.00 (reference) & & 1.00 (reference) & \\
\hline Overweight/obese & $1.52(0.72-3.21)$ & 0.272 & $1.50(0.68-3.33)$ & 0.321 \\
\hline \multicolumn{5}{|l|}{ Homocysteine $^{\dagger}$} \\
\hline Underweight/normal weight & 1.00 (reference) & & 1.00 (reference) & \\
\hline Overweight/obese & $0.90(0.41-1.96)$ & 0.783 & $0.74(0.31-1.77)$ & 0.503 \\
\hline \multicolumn{5}{|l|}{ TNF-alpha } \\
\hline Underweight/normal weight & 1.00 (reference) & & 1.00 (reference) & \\
\hline Overweight/obese & $0.70(0.26-1.88)$ & 0.479 & $0.71(0.25-1.97)$ & 0.507 \\
\hline \multicolumn{5}{|l|}{ Fibrinogen } \\
\hline Underweight/normal weight & 1.00 (reference) & & 1.00 (reference) & \\
\hline Overweight/obese & $1.16(0.54-2.51)$ & 0.706 & $1.40(0.62-3.11)$ & 0.419 \\
\hline \multicolumn{5}{|l|}{ Fasting insulin } \\
\hline Underweight/normal weight & 1.00 (reference) & & 1.00 (reference) & \\
\hline Overweight/obese & $8.03(3.86-16.71)$ & $<0.001$ & $9.13(4.07-20.49)$ & $<0.001$ \\
\hline \multicolumn{5}{|l|}{ Fasting glucose } \\
\hline Underweight/normal weight & 1.00 (reference) & & 1.00 (reference) & \\
\hline Overweight/obese & $1.27(0.60-2.69)$ & 0.540 & $1.39(0.59-3.25)$ & 0.453 \\
\hline \multicolumn{5}{|l|}{ HOMA-IR } \\
\hline Underweight/normal weight & 1.00 (reference) & & 1.00 (reference) & \\
\hline Overweight/obese & $8.03(3.86-16.71)$ & $<0.001$ & $8.84(3.98-19.64)$ & $<0.001$ \\
\hline \multicolumn{5}{|l|}{ Leptin } \\
\hline Underweight/normal weight & 1.00 (reference) & & 1.00 (reference) & \\
\hline Overweight/obese & $5.55(2.68-11.44)$ & $<0.001$ & $11.09(4.05-0.35)$ & $<0.001$ \\
\hline \multicolumn{5}{|l|}{ Total cholesterol } \\
\hline Underweight/normal weight & 1.00 (reference) & & 1.00 (reference) & \\
\hline Overweight/obese & $1.63(0.79-3.37)$ & 0.189 & $1.68(0.77-3.66)$ & 0.189 \\
\hline \multicolumn{5}{|l|}{ LDL-c } \\
\hline Underweight/normal weight & 1.00 (reference) & & 1.00 (reference) & \\
\hline Overweight/obese & $5.50(2.67-11.32)$ & $<0.001$ & $5.98(2.78-12.74)$ & $<0.001$ \\
\hline \multicolumn{5}{|l|}{ HDL-c $\mathrm{c}^{\ddagger}$} \\
\hline Underweight/normal weight & 1.00 (reference) & & 1.00 (reference) & \\
\hline Overweight/obese & $2.76(1.37-5.56)$ & 0.004 & $2.82(1.31-6.06)$ & 0.008 \\
\hline \multicolumn{5}{|l|}{ Triglycerides } \\
\hline Underweight/normal weight & 1.00 (reference) & & 1.00 (reference) & \\
\hline Overweight/obese & $1.63(0.79-3.38)$ & 0.189 & $1.92(0.89-4.17)$ & 0.098 \\
\hline
\end{tabular}


Note: OR, odds ratio; 95\% CI, 95\% confidence interval; CRP, C-reactive protein; TNF- $\alpha$, tumor necrosis factor alpha; HOMA-IR, homeostasis model assessment index-insulin resistance; LDL-c, low-density lipoprotein cholesterol; HDL-c, high-density lipoprotein cholesterol.

*All logistic regression models were adjusted for age, female sex, family income, mother's education, and physical activity. ${ }^{\dagger}$ Model also adjusted for vitamin B12 due to the confounding influence of Vitamin B12 on the homocysteine metabolism. ${ }^{\star}$ Multivariable logistic regression model considering cardiometabolic risk factors $\left(<25^{\text {th }}\right.$ percentile $)$ as outcome. 